\title{
Removal of miniplates following facial trauma and orthognathic surgery: a 3-year study
}

\author{
Na-Ra Shin ${ }^{1}$, Ji-Su Oh${ }^{1}$, Sang-Hun Shin², Su-Gwan Kim* \\ ${ }^{1}$ Department of Oral and Maxillofacial Surgery, College of Dentistry, Chosun University, Gwangju, Korea \\ ${ }^{2}$ Department of Dentistry, Graduate School of Chosun University, Gwangju, Korea
}

The purpose of this study was to determine the cause and risk factors of removing bone plateby investigating and analyzing 359 patients who underwent reduction of fracture or orthognathic surgery with bone plate insertion over the past 3 years. Patients were evaluated with respect to age, smoking status, reason for insertion of plates, the numbers of inserted plates, sites of insertion, time between insertion and removal, reasons for removal of plates. The removal rate of bone plates was $33.1 \%$. Of these, $17.0 \%$ of patients had clinical symptoms which led to remove plates. The removal rate of men was $29.9 \%$ and the rate of women was $39.2 \%$. There were high removal rates from less than 20 s (45.8\%) and 20s (34.4\%) those who are relatively young age group. On the other hand people in their 50 s had a removal rate of $27.8 \%$ which was higher than those in their 60 s with a rate of $20.7 \%$. The removal rate of bone plate inserted into the mandible was $33.5 \%$, and the removal rate of bone plate inserted into the maxilla was $34.7 \%$. The mean period between the insertion and removal of bone plate was 10.9 months. The main reason for the removal of bone plate was the patient's requirement (44.5\%). The most common cause of clinical symptoms was infection (22.7\%). Infection was manifested within about a year and led to the plate being removed. Therefore, lowering the possibility of infection after surgery could decrease the removal rate of bone plate.

Key Words: Bone plate, Facial bones, Fractures, bone, Orthognathic surgery

(c) This is an open-access article distributed under the terms of the Creative Commons Attribution Non-Commercial License (http://creativecommons.org/licenses/by-nc/4.0) which permits unrestricted noncommercial use, distribution, and reproduction in any medium, provided the original work is properly cited.

\section{서 론}

19세기 후반부터 안면골의 골판과 나사를 이용한 내고정술 이 보고된 바 있으며, 지난 40 년 이상의 기간 동안 구강악안 면 영역에서 일상적으로 골판을 사용하여 견고고정을 시행하 여 왔다[1,2]. 소형금속판을 이용한 견고고정을 시행할 때의 이 점으로는 골절부의 안정적인 고정을 얻을 수 있고, 악간 고정술 이 필요하지 않아 호흡 곤란 등의 합병증의 발생 가능성이 적다 [3]. 현재 구강악안면 영역에서 주로 사용되는 골판은 대부분 티 타늄 합금으로 만들어진다. 이는 티타늄이 조직 적합성이 우수
하며, 부식에 강하고 비독성이며, 알러지 반응이 없기 때문이 다[1]. 생물학적으로 불활성을 보이는 티타늄도 골유합이 완료 된 후 체내에 계속 남아 있을 경우 여러 합병증을 나타낼 수 있 다. 알려진 합병증으로는 감염, 통증, 판의 노출, 연조직의 미 란, 촉지성 등의 불편감을 야기할 수 있다[4-6]. 이러한 이유 때 문에 Champy 등[2]과 Cawood [7]는 골판 삽입 후 3개월 후에 판을 제거할 것을 제안했다. 그러나 Jackson 등[8]과 Brown 등 [5]은 골판의 제거는 필수적인 것은 아니고 단지 증상이 있을 경우에만 시행하여야 한다고 주장했다. 1991년에 Strasbourg Osteosynthesis Research Group은 "기능을 하지 않는 플레이

Received November 16, 2018; Revised November 27, 2018; Accepted November 28, 2018

Corresponding author: Su-Gwan Kim, Department of Oral and Maxillofacial Surgery, College of Dentistry, Chosun University, 303 Pilmundaero, Dong-gu, Gwangju 61452, Korea.

Tel: +82-62-220-3819, Fax: +82-62-228-7316, E-mail: sgckim@chosun.ac.kr

Copyright $\odot$ 2018, Oral Biology Research Institute 
트는 환자에게 과도한 위험을 초래하지 않는다면 제거되는 것 이 바람직하다” 고 권고하였다[9]. 현재는 증상이 있는 골판은 제거되어야 한다는 주장에는 이견이 없지만 어떤 골판에서 증 상이 발생할지는 예측할 수 없다.

본 연구의 목적은 3년간 외상과 악교정 수술로 구강악안면 영 역에 골판을 삽입하고 제거한 환자들을 분석하여 골판 제거의 원인과 그 위험 요소를 파악하기 위함이다.

\section{대상 및 방법}

본 실험은 조선대학교 치과병원 생명윤리심의위원회의 심의 하에(승인번호: CUDHIRB-1703-002) 진행되었다.

2015년 1월부터 2017년 12월까지 3년간 조선대학교 치과병 원에서 골판삽입을 동반한 골절의 정복술 및 악교정 수술을 시 행한 환자와 골판제거술을 시행한 환자를 조사하였다. 조사는 조선대학교 치과병원 데이터베이스 검색으로 이루어졌다. 골판 을 삽입한 환자는 359 명이었고, 제거한 환자는 그 중 119명이 었다. 본원에서 골판의 삽입술을 시행하지 않고 본원에서 제거 술을 시행한 환자는 제외되었으며, 3 년간의 조사기간 동안 삽 입술과 제거술을 모두 시행한 환자만을 포함시켰다. 또한 감염 의 가능성이 높은 조절되지 않는 당뇨를 않고 있는 환자, 면역억 제제를 복용하고 있는 환자와 골유합을 저해할 수 있는 장기간 스테로이드 제제를 복용하고 있는 환자 등은 조사에서 제외하 였다. 환자들의 나이, 흡연 유무, 골판 삽입의 이유, 골판의 삽입 개수, 골판의 삽입 부위, 골판 삽입과 제거 사이의 기간, 골판의 제거 이유를 조사하였다. 하악골의골판 삽입 부위는 다음과 같 이 분류되었다.

정중부: 골절선이 하악 중절치 사이에 존재하는 경우

부정중부: 양측 견치 사이에 골절선이 존재하는 경우

하악체부: 부정중부 후방의 구치부에 골절선이 존재하는 경우

하악각: 하악체부 후방과 상행지 하방에 골절선이 존재하는 경우

상행지부: 하악지의 전방 및 후방경계가 수평적으로 연결되 거나 하악절흔에서 하악하연까지 수직으로 연결된 경우

과두하부: 관절돌기 경부하방에 하악절흔에서 하악지의 후방 으로 골절선이 존재하는 경우

이부: 골절선이 치조골로 연장되지 않으며 하악골 첨부 상방 으로 수평적 또는 경사지게 형성된 경우

환자들은 골판의 삽입 이유에 따라 외상 그룹과 악교정 수술 그룹 둘로 분류되었다. 외상 그룹에는 하악골과 상악골 골절 환 자가 포함되었다. 악교정 수술 그룹에는 Le-Fort I 골절술, 하악 골의 교정 수술이 포함되었다.

골판의 제거 이유는 다음 6 가지로 분류되었다.
감염: 종창, 동통, 창상의 열개, 농양의 배출 등의 명확한 감염 의 증거가 있는 경우

판이나 나사의 유지 실패: 명확한 감염의 증상은 없으나 방사 선학적으로 판이나 나사의 파절, 나사의 풀림 등의 증상이 관찰 된 경우

통증이나 불편감: 임상적, 방사선학적으로 명확한 감염의 증 상은 없으나 환자가 느끼는 통증이나 불편감으로 골판을 제거 하는 경우

촉지성: 삽입된 골판이 감지되어 환자의 요구로 골판을 제거 하는 경우

보철 수복: 명확한 감염의 증상이 없고 환자의 통증이나 불편 감도 존재하지 않지만 임플란트 등의 보철 수복 시 삽입된 골판 이 방해가 되는 경우

환자의 요구: 상기 기술된 임상적 증상이 없고 보철 수복으로 인한 골판의 제거가 요구되지 않지만 환자의 요구에 의해서 골 판을 제거하는 경우

\section{결 과}

3년간 골판을 삽입한 환자의 수는 359명이었으며, 골판을 제 거한 환자의 수는 119 명(33.1\%)이었다. 삽입된 골판의 개수는 790개이며, 제거된 골판은 266개 (33.7\%)였다. 이 중 외상 그 룹의 환자는 206명 중 62명(30.1\%)이 골판을 제거하였고 제거 된 골판은 396개 중 124 개(31.3\%)였다. 악교정 수술 그룹에서 는 153 명 중 57명(37.3\%)이 골판을 제거하였고 제거된 골판은 394 개 중 142 개(36.0\%)였다(Fig. 1).

359 명 전체 환자의 나이는 평균 30.9세였고 이 중 외상 그 룹 환자의 나이는 평균 35.9세, 악교정 수술 그룹 환자의 나이 는 평균 24.2세였다(Fig. 1). 19세까지의 나이에서 48 명 중 22

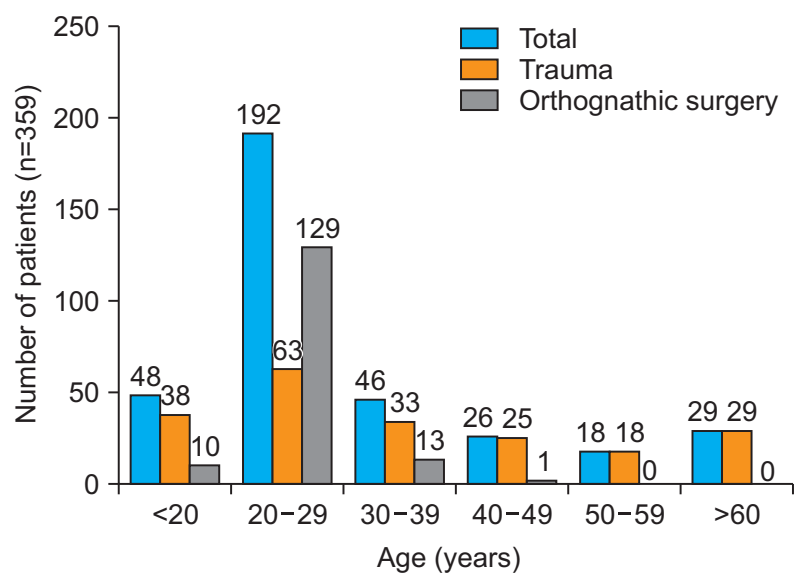

Fig. 1. Age distribution. 
명(45.8\%)의 골판을 제거하였으며, 20대에서 192명 중 66 명 (34.4\%), 30대에서 46명 중 12명(26.1\%), 40대에서 26명 중 8 명(30.8\%), 50대에서 18 명 중 5명(27.8\%), 60대 이상에서 29명 중 6 명 $20.7 \%$ )이 골판을 제거하였다. 전체 환자 중 남자는 234 명이었고 여자는 125 명이었다. 남자 중 골판을 제거한 환자는 70명(29.9\%)이었고 여자는 49명(39.2\%)이었다(Table 1).

골판을 삽입한 전체 환자 359 명 중 흡연자는 102 명(28.4\%)이 었으며, 흡연자 중 골판을 제거한 환자는 26 명 $(25.5 \%)$ 이었다.

전체 삽입된 골판 790개 중 하악에 삽입된 골판의 개수는 692 개(87.6\%)였으며, 상악은 98개(12.4\%)가 삽입되었다. 하악에서 제거된 골판의 수는 232 개(33.5\%), 상악에서는 34개(34.7\%)가 제거되었다. 외상 그룹에서는 제거된 골판 중 118 개(95.2\%)가 하악에서 제거되었고, 6 개(4.8\%)가 상악에서 제거되었다. 악교 정 수술 그룹에서는 142 개 중 114 개(80.3\%)가 하악에서 제거되 었고, 28개(19.7\%)가 상악에서 제거되었다(Table 2).

하악골 내에서는 하악골 정중부에서 110 개 중 18 개(16.4\%), 부정중부에서 148 개 중 60 개(40.5\%), 하악체부에서 324 개 중 123 개( $40.0 \%)$, 하악각에서 88개 중 25개(28.4\%), 상행지부에 서 2 개 중 1 개(50.0\%), 과두하부에서 5개 중 2개( $40.0 \%)$, 이부 에서 15 개 중 3 개 $(20.0 \%)$ 가 제거되었다.

골판 삽입술 후 제거술까지의 기간은 평균 10.9 개월이었으 며, 외상 그룹에서 10.2개월, 악교정 수술 그룹에서 11.8 개월이 었다.

전체 환자 119 명의 골판 제거의 이유는 감염이 26 명(21.8\%), 판이나 나사의 유지 실패로 인해 제거한 환자가 6 명 $(5.0 \%)$, 통 증이나 불편감으로 제거한 환자는 14 명(11.8\%)이었다. 촉지성 을 호소하여 제거한 환자는 11 명(9.2\%)이었으며, 보철물 삽입 을 위해 골판을 제거한 환자는 8 명(6.7\%)이었다. 다른 임상 증 상이 없으나 환자의 요구로 제거한 경우는 53 명(44.5\%)이었다.

Table 1. Patients requiring plate removal by sex

\begin{tabular}{lccc}
\hline Removal status & Male & Female & Total \\
\hline Removed & 70 & 49 & 119 \\
Not removed & 164 & 76 & 240 \\
Total & 234 & 125 & 359 \\
\hline
\end{tabular}

Table 2. Plates removed by location

\begin{tabular}{lccc}
\hline Removal status & Maxilla & Mandible & Total \\
\hline Removed & 34 & 232 & 266 \\
Not removed & 64 & 460 & 524 \\
Total & 98 & 692 & 790 \\
\hline
\end{tabular}

이 중 외상 그룹 환자 62 명의 골판 제거의 이유는 감염이 20 명 (32.3\%), 판이나 나사의 유지 실패로 인해 제거한 환자가 5명 (8.1\%), 통증이나 불편감으로 제거한 환자는 11 명(17.7\%)이었 다. 촉지성을 호소하여 제거한 환자는 8명(12.9\%)이었으며, 보 철물 삽입을 위해 골판을 제거한 환자는 4 명(6.5\%)이었다. 다른 임상 증상이 없으나 환자의 요구로 제거한 경우는 13 명(21.0\%) 이었고, 위 6 가지 이유에 포함되지 않는 환자는 1명(1.6\%)이었 다. 이는 소아 하악골 골절 환자로서, 티타늄 플레이트의 유지가 성장에 영향을 미칠 가능성이 존재하여 제거하였다. 악교정 수 술 그룹 환자 57 명의 골판 제거의 이유는 감염이 6명 $(10.5 \%)$, 판 이나 나사의 유지 실패로 인해 제거한 환자가 1 명 $(1.8 \%)$, 통증이 나 불편감으로 제거한 환자는 3명(5.3\%)이었다. 촉지성을 호소 하여 제거한 환자는 3 명 $5.3 \%)$ 이었으며, 보철물 삽입을 위해 골 판을 제거한 환자는 4 명 $(7.0 \%)$ 이었다. 다른 임상 증상이 없으나 환자의 요구로 제거한 경우는 40명(70.1\%)이었다(Table 3).

\section{고 찰}

티타늄 골판을 이용한 악골의 고정은 악골의 유지에 매우 유 용하고 높은 강도와 생체적합성 덕분에 악안면 부위에 발생하 는 외상이나 악교정 수술 시에 주로 사용된다. 티타늄 골판은 생 체적합성이 좋기는 하나 감염이나 다른 불편감을 야기할 수 있 다. 하지만 현재까지 삽입된 골판을 제거하는 것에 대한 기준은 명확하지 않다. 본 연구에서는 골판을 삽입 또는 제거한 환자를 분석하여 골판의 제거율 및 흡연 유무, 골판이 삽입된 부위, 골 판의 삽입 후 제거까지의 기간,골판의 제거 이유 등을 분석하여 다른 연구들과 비교하였다.

Table 3. Number of patients by reasons for plate removal

\begin{tabular}{lccc}
$\begin{array}{c}\text { Reason for plate } \\
\text { removal }\end{array}$ & Trauma & Orthognathic & Total \\
\hline Infection & 20 & 6 & 26 \\
Prosthetic restoration & 4 & 4 & 8 \\
Pain/discomfort & 11 & 3 & 14 \\
Palpability & 8 & 3 & 11 \\
Patients' demand & 13 & 40 & 53 \\
$\begin{array}{l}\text { Plate fracture/ } \\
\text { screw loosening }\end{array}$ & 5 & 1 & 6 \\
Other reason \\
$\quad$ growth disorder)
\end{tabular}




\section{제거율}

기존에 발표된 여러 문헌에서 골판 삽입 후 제거율은 $6.1 \%$ 에 서 23.4\%를 보였다[3,4,9-13]. 본 연구에서 골판을 삽입한 환자 중 $33.1 \%$ 가 골판제거술을 경험하였고 골판의 제거율은 $33.7 \%$ 로, 기존의 연구들에 비해 높은 제거율을 보였다. 이는 본원의 정책상 골판을 제거해야 할 명백한 증상이 없는 환자라도 환자 본인이 원할 시 골판제거술을 시행하는 것이 원인이라고 생각 된다. 또한 이신경과 근접하지 않거나 구외접근이 필요치 않는 부위에 삽입된 골판 제거 시 전신마취를 하지 않고 국소마취하 에 골판을 제거하는 것도 골판 제거율이 높은 것에 대한 원인이 라고 생각된다.

\section{나이}

나이가 증가함에 따라 골판의 제거율은 비례하여 낮아지 진 않았으나 비교적 어린 나이인 20대 미만(45.8\%)과 20대 (34.4\%)에서 높은 제거율을 보였으며, 50 대(27.8\%)와 60 대 이 상 $(20.7 \%)$ 에서 상대적으로 낮은 제거율을 보였다. 외상 그룹에 서는 20 대 미만에서 $44.7 \%, 20$ 대에서 $30.2 \%, 30$ 대에서 $21.2 \%$, 40 대에서 $32.0 \%, 50$ 대에서 $27.8 \%, 60$ 대 이상에서 $20.7 \%$ 의 제 거율을 보였다. 악교정 수술 그룹에서는 20대 미만에서 $50.0 \%$, 20 대에서 $36.4 \%, 30$ 대에서 $38.5 \%, 40$ 대 이상에서는 $0 \%$ 의 제 거율을 보였다. Manor 등[9]은 악교정 수술을 받은 환자에서 나 이가 많을수록 제거율이 높아져 나이는 악교정 수술을 경험한 환자에서 골판의 제거에 대한 통계적으로 유의한 위험인자라고 보고하였다. 하지만 본 연구에서는 그러한 연관성을 발견하지 못하였다.

\section{성별}

본 연구에서 전체 환자 중 남자의 골판 제거율은 $29.9 \%$ 이었 고 여자는 $39.2 \%$ 이었다. Little 등[11] 연구를 포함한 대부분의 연구들은 성별에 따라 통계적으로 유의한 차이를 보이지 않는 다고 보고하였다. 다만, Manor 등[9]은 여성이 골판 제거에 대 한 두 번째로 중요한 위험요소라 보고하였고, Falter 등[14]도 여 성에서 판의 제거율이 높다고 보고하였다. 이는 본 연구의 결과 와 부합하였다.

\section{흡연}

흡연은 일반적으로 상처 치유를 저하시키며 술 후 감염 등의 합병증을 발생시키는 가능성을 증가시키는 것으로 알려져 있
다. 담배 연기에는 4,000 가지 이상의 독성 물질이 존재하며 신 체에 다양하게 국소적 또는 전신적인 영향을 준다. 일산화탄소 는 헤모글로빈의 산소 운반에 영향을 미치며, 니코틴은 혈관 수 축을 야기하여 조직에 전달되는 혈액의 양을 저하시킨다. Alhpa 등[15]을 포함한 여러 문건에서 흡연자는 비흡연자에 비해 술 후 상처 치유가 지연되었으며, 감염의 가능성이 높다고 보고하 였다. 본 연구에서도 골판을 제거한 환자 119 명 중 감염으로 인 해 골판을 제거한 환자는 27 명(22.7\%)이었고 흡연자의 경우에 는 26 명 중 8 명(30.8\%)으로 흡연자에서 감염으로 인한 골판의 제거율이 높았다.

\section{골판이 삽입된 위치}

하악골에 삽입된 골판은 $33.5 \%$ 의 제거율을 보였으며, 상악골 에 삽입된 골판은 $34.7 \%$ 의 제거율을 보였다. 이는 Little 등[11] 의 연구와는 일치하지 않으나, Francel 등[16], Brown 등[5], Rallis 등[12]의 연구와는 일치하는 결과를 보였다.

하악골 내에서는 상행지부에서 제거율이 $50 \%$ 로 높았으나 이 는 표본의 수가 2개로 적었다. 이를 제외하고는 부정중부에서 $40.5 \%$ (148개 중 60개)로 제일 높았다. 이는 Brown 등[5]의 연 구와는 일치하는 결과를 보였다. 하지만 우리의 연구와 대조적 인 결과를 보이는 연구들도 존재한다. Bhatt와 Langford [17] 과 Francel 등[16]은 하악각에서 가장 높은 제거율을 보고하였 다. 이 연구에서 감염으로 인한 하악골 부정중부의 골판 제거율 은 $34.4 \%$ 인데 반해, 하악각에서는 감염으로 인한 골판 제거율 이 $58.3 \%$ 에 달했으며, 하악각에 골판을 삽입한 환자 25 명 중 골 절선이 지치를 포함하는 경우는 16 명이었다. 이는 골절 시 흔히 매복된 지치 주변으로 골절선이 형성되며, 골절 시 지치의 파절 이 동반되는 것도 감염 가능성 증가에 기여하는 것으로 생각된 다. 또한 하악각 골절 시 골판이외사선에 위치하는 경우에는 골 판이 얇은 점막 직하방에 위치하여 저작과 의치에서 반복된 외 상에 영향을 받기 쉽다는 것도 감염 가능성이 증가하는 원인 중 하나라고 생각된다[12].

\section{골판의 삽입과 제거 사이의 기간}

우리 연구에서 골판의 삽입과 제거 사이의 기간은 평균 10.9 개월이었다. 이 중 12 개월 이내에 골판을 제거한 환자는 86 명 (72.3\%)이었다. 이는 Little 등[11]이 보고했던 $71.4 \%$, Bhatt와 Langford [17]이 보고했던 $72 \%$ 의 1년 이내 제거율과 일치하는 결과를 보였다. 이는 골판의 제거가 요구되는 감염, 골편의 안정 실패, 통증 등의 여러 임상적 증상들이 1 년 이내에 주로 발생한 다고 생각할 수 있다. Brown 등[5]은 30개월 이상 증상이 없었 
던 골판의 경우 제거의 필요가 없다고 주장하였다.

\section{골판의 제거 이유}

이 연구에서 골판 제거의 주된 이유는 환자의 요구(44.5\%)였 다. 이는 골판 제거 시 접근이 용이한 경우 국소마취하 외래에서 제거술을 시행하는 본원 프로토콜 때문이라고 생각한다. 이는 전신마취를 하지 않으므로 환자의 부담이 적어 골판제거술에 대한 결정율이 높다. 이는 특히 상대적으로 젊은 악교정 수술 환 자에서 주된 골판 제거의 이유였다. $70.1 \%)$. 외상 그룹에서는 감 염(32.3\%)이 주된 이유이며, 이는 전체 골판 제거의 두 번째로 많은 원인이었다(21.8\%).

감염은 여러 연구에서 보고하는 골판 제거의 주요 원인이다. Bhatt와 Langford [17]과 Manor 등[9]은 감염으로 인한 골판 제거가 가장 빈번하다고 보고하였다. 다른 연구에서도 감염으 로 인한 골판 제거는 $12 \%-60 \%$ 에 달한다[4,18,19]. 본 연구에서 도 감염은 전체 환자 중 두 번째로 빈번한 골판 제거의 이유였으 며, 외상 그룹에서는 가장 주요한 원인이었다.

감염의 징후 없이 단순 통증 또는 불편감으로 골판을 제거한 경우는 14 명(11.8\%)이었다. 이 중 외상 그룹이 11 명으로 대부 분을 차지했고, 이 중 정중부와 부정중부에서 통증 또는 불편감 을 호소한 환자는 8 명이었다. 이는 저작 시 하악의 비틀림에 의 한 것이라고 생각된다. Nagase 등[4]은 안면 골격에 따라 위에 서 아래로 내려가면서 불편함이 감소하는 경향이 존재하며, 안 와상공, 안와하공, 이공 등 해부학적 구조물 주위에 위치된 골판 이 불편함을 야기한다고 보고하였다. 또한 추운 기후 때문에 불 편감이 발생하기도 한다. Thorén 등[13]의 연구에서는 골판 제 거의 주요한 이유는 주로 겨울에 발생하는 환자의 주관적인 불 편함 때문이었고, 이는 핀란드의 추운 기후에 의해 유발되었다 고 보고하였다.

Manor 등[9]은 감염 다음으로 빈번한 골판 제거의 이유는 촉 지성이라고 보고하였으며, 이는 특히 나이가 증가할수록 제거 율이 올라가고, 이는 피부의 탄력성이 떨어지기 때문이라고 보 고하였다. 본 연구에서는 119 명 중 11 명(9.2\%)의 환자가 촉지 성을 이유로 골판을 제거하였다. 나이는 18 세에서 28 세로 분포 하였고 평균 22.5세로 Manor 등[9]과는 일치하지 않는 결과를 보였다.

본 연구에서의 골판의 제거율은 $33.1 \%$ 로 기존의 다른 연구들 보다 높은 제거율을 보였다. 그러나 이는 임상적 증상이 없더라 도 환자가 제거술을 요구할 경우 수술을 시행하는 본원 프로토 콜이 원인이라고 생각된다. 또한 접근이 용이한 경우 국소마취 하 골판의 제거술을 시행하는 것도 높은 제거율의 원인이라고 생각한다. 임상적 증상이 없는 환자의 단순 요구 또는 보철 수복
을 위해 골판을 제거한 경우를 제외하면 실제 감염, 통증, 불편 감 등의 임상적 증상이 존재하여 골판을 제거한 경우는 $17.0 \%$ 로서 기존에 보고된 연구들과 비슷한 제거율을 보였다. 임상적 증상을 야기하는 가장 큰 원인은 골판 또는 술부의 감염이며, 이 는 약 1 년 이내에 증상이 발현되어 제거되었다. 흡연은 감염을 야기시킬 수 있는 원인으로 생각된다. 따라서 술 후 감염의 가능 성을 낮추는 것이 골판의 제거율을 낮출 수 있을 것이다.

\section{ACKNOWLEDGEMENTS}

This study was supported by research fund from Chosun University, 2018.

\section{CONFLICTS OF INTEREST}

The authors declare that they have no competing interests.

\section{ORCID}

\author{
Na-Ra Shin \\ https://orcid.org/0000-0002-8351-495X \\ $\mathrm{Ji}-\mathrm{Su} \mathrm{Oh}$ \\ https://orcid.org/0000-0002-8369-5025 \\ Sang-Hun Shin \\ https://orcid.org/0000-0002-3290-4261 \\ Su-Gwan Kim \\ http://orcid.org/0000-0002-0424-9984
}

\section{REFERENCES}

1. Haug RH. Retention of asymptomatic bone plates used for orthognathic surgery and facial fractures. J Oral Maxillofac Surg 1996;54:611-617. doi: 10.1016/S02782391(96)90644-8.

2. Champy M, Loddé JP, Schmitt R, Jaeger JH, Muster D. Mandibular osteosynthesis by miniature screwed plates via a buccal approach. J Maxillofac Surg 1978;6:14-21. doi: 10.1016/S0301-0503(78)80062-9.

3. Bakathir AA, Margasahayam MV, Al-Ismaily MI. Removal of bone plates in patients with maxillofacial trauma: a retrospective study. Oral Surg Oral Med Oral Pathol Oral Radiol Endod 2008;105:e32-e37. doi: 10.1016/j.tripleo. 2008.01.006.

4. Nagase DY, Courtemanche DJ, Peters DA. Plate removal in traumatic facial fractures: 13 -year practice review. Ann 
Plast Surg 2005;55:608-611. doi: 10.1097/01.sap.0000 189666.13860.c0.

5. Brown JS, Trotter M, Cliffe J, Ward-Booth RP, Williams ED. The fate of miniplates in facial trauma and orthognathic surgery: a retrospective study. Br J Oral Maxillofac Surg 1989;27:306-315. doi: 10.1016/0266-4356(89)90043-0.

6. Kahnberg KE, Engström H. Recovery of maxillary sinus and tooth sensibility after le Fort I osteotomy. Br J Oral Maxillofac Surg 1987;25:68-73. doi: 10.1016/0266-4356 (87)90159-8.

7. Cawood JI. Small plate osteosynthesis of mandibular fractures. Br J Oral Maxillofac Surg 1985;23:77-91. doi: 10. 1016/0266-4356(85)90057-9.

8. Jackson IT, Somers PC, Kjar JG. The use of Champy miniplates for osteosynthesis in craniofacial deformities and trauma. Plast Reconstr Surg 1986;77:729-736.

9. Manor Y, Chaushu G, Taicher S. Risk factors contributing to symptomatic plate removal in orthognathic surgery patients. J Oral Maxillofac Surg 1999;57:679-682. doi: 10. 1016/S0278-2391(99)90431-7.

10. Mosbah MR, Oloyede D, Koppel DA, Moos KF, Stenhouse D. Miniplate removal in trauma and orthognathic surgery--a retrospective study. Int J Oral Maxillofac Surg 2003;32:148-151. doi: 10.1054/ijom.2002.0344.

11. Little M, Langford RJ, Bhanji A, Farr D. Plate removal following orthognathic surgery. J Craniomaxillofac Surg 2015;43:1705-1709. doi: 10.1016/j.jcms.2015.07.010.

12. Rallis G, Mourouzis C, Papakosta V, Papanastasiou G, Zachariades N. Reasons for miniplate removal following maxillofacial trauma: a 4-year study. J Craniomaxillofac Surg 2006;34:435-439. doi: 10.1016/j.jcms.2006.07.001.

13. Thorén H, Snäll J, Kormi E, Lindqvist C, Suominen-Taipale L, Törnwall J. Symptomatic plate removal after treatment of facial fractures. J Craniomaxillofac Surg 2010;38:505510. doi: 10.1016/j.jcms.2010.01.005.

14. Falter B, Schepers S, Vrielinck L, Lambrichts I, Politis C. Plate removal following orthognathic surgery. Oral Surg Oral Med Oral Pathol Oral Radiol Endod 2011;112:737743. doi: 10.1016/j.tripleo.2011.01.011.

15. Alpha C, O'Ryan F, Silva A, Poor D. The incidence of postoperative wound healing problems following sagittal ramus osteotomies stabilized with miniplates and monocortical screws. J Oral Maxillofac Surg 2006;64:659668. doi: 10.1016/j.joms.2005.12.013.

16. Francel TJ, Birely BC, Ringelman PR, Manson PN. The fate of plates and screws after facial fracture reconstruction. Plast Reconstr Surg 1992;90:568-573.

17. Bhatt V, Langford RJ. Removal of miniplates in maxillofacial surgery: University Hospital Birmingham experience. J Oral Maxillofac Surg 2003;61:553-556. doi: 10.1053/joms. 2003.50108.

18. Haraji A, Motamedi MH, Moharamnejad N. Causes and incidence of miniplate removal following Le Fort I osteotomy. Eplasty 2009;9:e45.

19. Bhatt V, Chhabra P, Dover MS. Removal of miniplates in maxillofacial surgery: a follow-up study. J Oral Maxillofac Surg 2005;63:756-760. doi: 10.1016/j.joms.2005.02.005. 